\title{
Protecting altruism: a call for a code of ethics
}

\section{in British psychiatry}

\author{
SAMEER P. SARKAR and GWEN ADSHEAD
}

Codes of ethics have existed for medicine since the time of Hippocrates. However, a written code of ethics (like a written constitution) has so far eluded British psychiatry. In this editorial we discuss the arguments for and against a code of ethics as an essential aspect of our identity as medical professionals. Our professional identity as psychiatrists is coming under scrutiny from the General Medical Council, the emergence of the user movement and the proposals in the draft Mental Health Bill. At a time when psychiatry is seen increasingly as a guardian of public safety, there has never been a more pressing need for a code of ethics.

\section{MEDICAL IDENTITIES: TRADE OR PROFESSION?}

Professions differ from trades in important conceptual ways. The 'trade' argument suggests that psychiatrists are what users of services want them to be and - more importantly - are willing to pay for. Consumers negotiate with trades people for their services on an equal interpersonal footing. However, this approach is unconvincing in psychiatry, because mental health is not a commodity that can be bartered for, and therapeutic relationships are more complex because patients are additionally dependent and vulnerable. On this argument alone, psychiatry cannot be a trade and psychiatric patients cannot be consumers.

Professionals have a body of knowledge, a set of standards and an established value system. Professionals acquire their identity with their training, which may or may not be integrated with other social and personal identities. For example, if a call goes out on an aircraft flight asking for a doctor, what should the 'good' psychiatrist do? Is this different from what the 'good' doctor should do, or even the 'good' citizen? A psychiatrist who volunteers to help may be acting as much as a good citizen as a good doctor, since medically, he or she may be able to do very little.

A profession must have at least three basic components to maintain its standards: entry, education and exit (Dyer, 1999). The professional standards of practice for psychiatrists are laid out in published form in Good Medical Practice (General Medical Council, 2001) and Good Psychiatric Practice 2000 (Royal College of Psychiatrists, 2000). Professions such as medicine and law were formerly exempt from American anti-trust laws (Dyer, 1999); however, in 1975 a US Supreme Court decision ruled that 'learned professions' were no longer immune from anti-trust laws, and could thus be seen as 'trades'. This American example is a reminder that the nature of the financial contract between doctor and patient significantly influences both legal and professional relationships in medicine; and where relationships change, ethical duties and values may also change (Appelbaum, 1990).

Professions exist not only for their own benefit but also to promote the well-being of others, and this is the essence of the fiduciary duty unique to professionals. The altruistic element of professional identity runs in tandem with a specialised body of knowledge, and is encoded in the ethical principles of that profession (Sieghart, 1985).

\section{WHY HAVE A CODE OF ETHICS AT ALL?}

Fulford \& Bloch (2000) set out the arguments for and against having a code of ethics. Codes may protect and promote a profession, and enhance high standards of practice, based on ethical principles. However, codes may also be self-serving and inward-looking. They may also be derived without appeal to general moral norms or the views of the wider public, especially users of medical services (Beauchamp $\&$
Childress, 1994). The existence of a code may also induce a sense of complacency and encourage professionals to apply it in an unthinking way. Codes may actually reinforce bad practice, if this is the current norm. We know that the existence of a code of research ethics had little effect on the practice of medical members of the Nazi party. There appears to be little evidence that having a code of ethics prevents ethically unjustifiable practice.

However, absence of evidence is not evidence of absence. Relying on evidence of benefit as justification pays no attention to the intentions and characters of clinicians, which relates to the issue of professional identity and to altruism. The intention and values inherent in a code may protect as much as any consequentialist gain. As Fulford \& Bloch suggest, the existence of a code of ethics can protect the altruistic identity of the psychiatric professional, especially in politically oppressive contexts. A code of ethics may also help protect the interests of psychiatric patients by emphasising the importance of patient empowerment (World Psychiatric Association, 1996). A code of ethics is another way to maintain standards, even if it cannot ensure ethical behaviour.

\section{PSYCHIATRY AS A SPECIAL CASE}

Despite the caveats described above, several psychiatric professional bodies internationally have opted to have a separate code of ethics (derived from existing ethical codes in medicine), presumably in answer to the special ethical dilemmas encountered in psychiatry (American Psychiatric Association, 1973, 2001; World Psychiatric Association, 1977, 1996; Canadian Medical Association, 1980; Russian Society of Psychiatrists, 1994; Royal Australian and New Zealand College of Psychiatry, 1999). Why British psychiatry has not pursued this option is unclear; perhaps it is because British psychiatrists believe that it is not possible to police morality, least of all by a written set of rules. This view may have led to a different type of complacency from that described by Fulford \& Bloch: that ethical regulation should come from within the individual, and not be imposed from outside.

The most significant difference between medicine and psychiatry lies in the relative incapacity of psychiatric patients to make 
decisions for themselves. They are especially vulnerable not only because they lack capacity, but also because they are dependent on others to restore that capacity. There is a need for appropriately regulated paternalism in the case of patients who need care but are unable to ask for it. Furthermore, most mental disorders are of a chronic and relapsing nature. The loss of autonomy is not a discrete event but rather a chronic loss or a fluctuating level of autonomy. This reduced autonomy means that our patients are often in a long-term dependent relationship with carers, and their autonomy is 'interstitial' in so far as it is located in a network of relationships (Agich, 1993).

Patients' dependence on others may mean that their expressed views and wishes are ignored. Under current English law, unlike medical patients', psychiatric patients' competent refusals may be overridden (Sarkar \& Adshead, 2002) even if the intervention can cause direct 'harm' in terms of the patient's experience. This includes harm by inducing side-effects, forcible administration of medication and prolonged involuntary detention. Society gives psychiatrists power that no trade could ever have. Traders might cheat you in the course of their business, but they are not legally allowed to assault you.

Another direct source of harm to patients from psychiatric practitioners arises from boundary violations and the exploitation of vulnerability. This issue is so rarely discussed in British or European psychiatry that practitioners might be forgiven for thinking that this is a purely North American problem. However, General Medical Council data, and information available from voluntary groups and charities, suggest otherwise. Despite being proscribed in the Hippocratic oath, it is entirely legal in the UK to have a sexual relationship with a patient, so long as the patient is not detained. However, there is no reason to assume that non-detained patients, or out-patients, will be any less vulnerable than detained patients.

Psychiatry risks harming people by treating them unjustly. Patients who commit offences may be detained on treatment grounds for longer than they would have served in prison. Patients may not be released from hospital (and under the draft Bill, may have to be admitted) if they present a risk to others, so that the primary purpose of detention is the benefit of third parties rather than the patient. The policy

SAMEER P. SARKAR, MD, Institute of Psychiatry at the Maudsley Hospital, London; GWEN ADSHEAD, MRCPsych, Broadmoor Hospital, Crowthorne, UK

Correspondence: Sameer P. Sarkar, Broadmoor Hospital, Crowthorne, Berkshire RG45 7EG, UK

(First received 24 May 2002, final revision 25 November 2002, accepted 27 November 2002)

of the Royal College of Psychiatrists with regard to risk assessment is that the clinician has a responsibility to take action with a view to ensuring that risk is reduced (Royal College of Psychiatrists, 1996). It is a matter of justice that people should know when they are being assessed for possible detention, and there is a need for transparency during the risk assessment.

In the absence of moral guidance from professional bodies, practical guidance has to come from various codes of practice and conduct. An example is the nonstatutory Code of Practice accompanying the Mental Health Act 1983. Although Gunn (1996) equates a code of ethics with a code of practice for trade unions, the trade $v$. profession distinction above tells us that this may be an oversimplification.

At some point, codes of conduct or practice are not sufficient for psychiatrists, and there is a need for a code of ethics that serves a different, if not wider, moral domain. A code of ethics might help to preserve the link with altruism, which is arguably the defining intention of the profession. This is important because users of health services want professionals to intend to do them good, as well as actually to do them good. Users of mental health services have to trust psychiatric professionals to protect their interests when they are not well enough to do so for themselves.

Finally, there is the question of multiple and conflicting duties and values in psychiatry - the so-called 'two hats' problem. Current legislative approaches in the UK seem to favour the value claims of third parties over those of people with mental illnesses, on the grounds of risk. This approach is in direct contradiction to the values espoused in both the Declaration of Madrid (World Psychiatric Association, 1996) and the National Service Framework (Department of Health, 1999).

\section{PROTECTING ALTRUISM}

The new mental health legislation proposals see the professional role of psychiatry as treating for risk, especially risk to others. Pitted against risk, the interests of the individual patient may come a poor second and ordinary moral claims of patients may be set aside. One can argue that it is 'good' for people not to be a risk to others, although this is not an argument that is applied to the general, non-mentally ill population. However, the traditional altruism of the medical role is addressed to patients, not to the public at large. Treatment to make others feel safer risks treating patients merely as a means to an end, in the Kantian sense.

If our traditional professional identity is so threatened, then a code of ethics might provide a framework for stability and further development. The establishment of such a code, sensitively debated and reflective of the values that are important to us, could be useful in setting standards and in training future psychiatrists. It might also assist with exploring the issue of diversity of values. It is not enough to acknowledge that values may clash: it is also necessary to understand why different groups of people may have different sets of values and to respect the difference. Recently, the Department of Health has (as part of the National Institute for Mental Health in England values framework) asked the College to provide 'a statement of professional values' for psychiatry. Although it cannot be guaranteed that our set of values will find favour with the Government, this may be a particularly opportune moment to develop our own code of ethics, reflecting the diversity of values in clinical practice.

How would a code help? It is true that it might not prevent poor practice. Furthermore, what should happen when the code is violated? Should violations be dealt with internally by the profession, or through a quasi-judicial sanction? Adoption of a code would raise many questions like these, not all of which can be answered here. It is our contention nevertheless that a voluntary code of ethics and self-regulation makes a profession strong and less open to outside interference. 
The General Medical Council's published maxim is 'Protecting patients, guiding doctors'. This ideally should also be the maxim of psychiatric practice. Sadly, it seems that as a profession we are being invited to endorse an ethical position that 'guides doctors to protect the public'. What we need is to define our ethical identity as psychiatrists, based on a system of values that are clinically meaningful and respectful of diversity. We may then be able to protect our medical identity while acknowledging that psychiatric practice has ethical dilemmas distinct from ordinary medical ethics.

\section{DECLARATION OF INTEREST}

None.

\section{REFERENCES}

Agich, G. (1993) Autonomy and Long-Term Care. Oxford: Oxford University Press.
American Psychiatric Association (1973) The Principles of Medical Ethics. With Annotations Especially Applicable to Psychiatry. Washington, DC: APA.

- (200I) The Principles of Medical Ethics. With Annotations Especially Applicable to Psychiatry (13th edn) Washington, DC: APA

Appelbaum, P. S. (1990) The parable of the forensic psychiatrist: ethics and the problem of doing harm. International Journal of Law and Psychiatry, 13, 249-259.

Beauchamp, T. \& Childress, J. (1994) Principles of Biomedical Ethics (4th edn). Oxford: Oxford University Press.

Canadian Medical Association (1980) Code of Ethics annotated for psychiatry. Canadian Journal of Psychiatry, 25, 432-438.

Department of Health (1999) The National Service Framework for Mental Health. Modern Standards and Service Models. London: Department of Health.

Dyer, A. (1999) Psychiatry as a profession. In Psychiatric Ethics (3rd edn) (eds S. Bloch, P. Chodoff \& S.A. Green), pp. 67-79. Oxford: Oxford University Press.

Fulford, K.W. M. \& Bloch, S. (2000) Psychiatric ethics codes, concepts and clinical practice skills. In New Oxford Textbook of Psychiatry (eds M. Gelder, N. Andreasen \& J Lopez-lbor), pp. 27-32. Oxford: Oxford University Press.
General Medical Council (200I) Good Medical Practice. London: General Medical Council.

Gunn, J. (1996) Commentary: comparative forensic psychiatry - USA vs. UK. Criminal Behaviour and Mental Health, 6, 45-48.

Royal Australian and New Zealand College of Psychiatry (1999) RANZCP Code of Ethics. Australasian Psychiatry, 7, 108

Royal College of Psychiatrists (1996) Assessment and Clinical Management of Risk of Harm to Other People. (Council Report CR53). London: Royal College of Psychiatrists.

— (2000) Good Psychiatric Practice 2000 (Council Report CR83). London: Royal College of Psychiatrists.

Russian Society of Psychiatrists (1994) The Code of Professional Ethics of the Psychiatrist. Reprinted (1999) in Psychiatric Ethics (eds S. Bloch, P. Chodoff \& A. Green) (3rd edn), pp. 526-531. Oxford: Oxford University Press.

Sarkar, S. P. \& Adshead, G. (2002) Treatment over objection: minds, bodies and beneficence. Journal of Mental Health Law, 7, 105-118.

Sieghart, P. (1985) Professions as the conscience of society. Journal of Medical Ethics, II, I17-122.

World Psychiatric Association (1977) Declaration of Hawaii. Elmhurst, NY: WPA.

— (1996) Declaration of Madrid. Elmhurst, NY: WPA 